\title{
El mito del hombre en lobo: del versipellis latino al lobisón en cuentos argentinos contemporáneos
}

\author{
Norma N. Porto de Farias y Olga N. Trevisán
}

La creencia en el licántropo tiene origenes remotos y hunde sus raíces en la cultura grecolatina, de donde extraemos las primeras fuentes occidentales de las referencias hechas por gramáticos, historiadores filósofos y escritos literarios ${ }^{\prime}$.

Extendida por todos los pueblos europeos, con la conquista, llega a América y se difunde por países como Argentina, Brasil y Paraguay donde la zoantropía del yaguareté-abá, indio-tigre, de las zonas guaranies apoya la existencia de la creencia inclusive en la época prehispanica².

La simbiosis cultural origina la leyenda del lobisón, en Argentina y Uruguay; luisón, en Paraguay; lobishome, en Brasil. La ausencia de lobos producirá algunas variantes: la mutación se hará en forma de perro, cerdo o aguará-guazú, especie hoy casi en extinción por la matanza a que fue sometida por su identificación con el lobisón. Como afirma Alfredo Schroeder la licantropía se transformará en América en una Kinantropia ${ }^{3}$, sin embargo su denominación (lobisón, luisón, lobishome), conserva la etimología latina de lupus: lobo.

El mito zoantrópico del hombre-lobo ha pasado del hipotexto de la oralidad a otros géneros discursivos como la literatura, la historieta, la radio, la música y el cine que lo recontextualizan construyendo nuevas significaciones. Este proceso se origina en la literatura grecolatina: los relatos de Ovidio y Petronio pueden ser considerados textos fundacionalessegún el concepto de Eliseo Verón ${ }^{4}$.

El estudio del fenómeno, conocido como licantropía ya en la antiglledad, fue silenciado en la Edad Media por la reprobación de la Iglesia que condenaba el licantropismo como un hecho demoníaco. A partir de fines del Siglo XIX, las investigaciones antropológicas y folcloricas se interesaron en las creencias, mitos y relatos de hombres-lobo como cuna constante del folclore de casi todos los pueblos. A partir de entonces esta matriz narrativa de la oralidad emerge en los discursos literarios y massmediáticos de la radio y el cine. En el siglo $\mathrm{XX}$ encontramos un renovado interés por la temática. La rica galería de hombres-lobo del cine y la literatura se inserta en un fenómeno cultural más amplio: el espacio teratológico de la aparición de monstruos, algunos de ellos creados en la literatura gótica, que se entrecruzan y mezclan en el discurso cinematográfico como un desafio a la racionalidad y como expresión de la alteridad.

\footnotetext{
'Herodoto: Historia IV,105; Platón: República, VIII; Pomponio Mela, Geografia,II, 8, 7; Apolodoro de Atenas: Biblioteca,III, 12,5; Plinio el Viejo, Historia Natural, VIII, 22.

2 Granada, Daniel. Supersticiones del Rio de la Plata. Montevideo, Barreiro y Ramos, 1896. Blache, Martha. Andlisis estructural de una creencia de la zona guaranitica: el lobison. En Cuadernos del Instituto Nacional de Antropología N’ 8, Bs. As., M. C. y E. de la República Argentina, Dirección Nacional de Investigaciones Culturales, 1972-1978.

3 Schroeder, Alfredo: Del "llcantropos" griego al "lobizon" americano. En Actas del VIII Simposio Nacional de Estudios Clásicos, Tucumán, Imprenta de la FAU, 1987.

${ }^{4}$ Verón, E: La semiosis sacial. Fragmentos de una teorta de la discursividad. Barcelona, Gedisa, 24 reimp., 1998. p.27.
} 
Los discursos argentinos contemporáneos de la radio, el cine, la música popular, la historieta, el teatro, la novela, pero sobre todo el cuento, recrean profusamente el motivo del lobisón.

Es nuestro propósito señalar la trama de las diversas significaciones y transformaciones semánticas operadas en el núcleo narrativo metamorfosis hombre-lobo.

En la selección del corpus se tomaron los primeros textos escritos literarios que aluden a licántropos, aquellos que tienen un desarrollo temático y no simples referencias tópicas: Las metamorfosis, de Ovidio y El Satiricón, de Petronio.

Desde este punto de partida, se hizo un recorte espacio-temporal en la trama interdiscursiva, centrando nuestro interés en los cuentos argentinos contemporáneos: los homónimos El lobizón de Horacio Quiroga, S. P. Bayona, Manuel Mujica Láinez y María Amalia Casco Encinas, Licantropia de Enrique Anderson Imbert, El lobisón de Horacio Riveros Sosa, Antes de que amanezca de Diego Angelino, Fases de la Luna de Sara Gallardo, Un lobizón en los fortines de Ricardo Ríos Ortiz, Lobizones de Justo P. Sáenz y La hilacha de Thay Morgenstern.

Esta selección incluye cuentos fantásticos. Por cuestión de extensión no se analizan los relatos adaptados a un receptor infanto-juvenil, que son numerosos en la última década, ni los humorístico-satíricos 5 .

\section{El versipellis, hombre-lobo, en la literatura latina}

Ovidio, en las Metamorfosis, I,163-252, introduce la leyenda de Licaón, rey de Arcadia, transformado en lobo como castigo divino por impiedad, inserto al final del mito de las edades y haciendo de engarce entre la paulatina degradación humana de la edad de hierro y la escatología del diluvio. La perversidad del rey arcadio y de toda su estirpe tiene un referente y origen celeste, la gigantomaquia.

Los Gigantes que aspiraron al reino de Júpiter, fueron fulminados por el rayo divino y de su sangre nació una estirpe de hombres impios y violentos, ávidos de matanza. El arquetipo de esta especie humana es Licaón cuya familia es destruida de la misma manera que la familia de los Gigantes por el rayo, pero que representa el comportamiento generalizado de toda la humanidad aniquilada por el diluvio a causa de su envilecimiento. Escatología, purga por el fuego y el agua y renovatio purificadora enmarcan el relato de Licaón.

El episodio refiere que, habiendo observado Júpiter los crimenes e infamias que sucedían en la tierra, decidió visitarla. Después de recorrerla y encontrar numerosos vicios, llegó hasta el palacio de Licaón, y sin ocultar su divinidad, pidió hospitalidad. Alli el rey se burló de él y proyectó matarlo mientras dormía para comprobar su condición divina; pero antes, sirvió en la cena carne humana, los miembros de un rehén recién degollado. El Dios indignado, lo transformó en lobo.

\footnotetext{
${ }^{3}$ Este trabajo es parte de un proyecto más amplio: Persistencia y transformación del mito de la metamorfosis del hombre en lobo, en relatos de la literatura latina y en producciones literarias y cinematográfica argentinas, que incluye, además de los cuentos, otros géneros discursivos: la novela, la historieta, el cine, la música popular, el discurso periodistico y la recopilación de relatos orales.
} 
El genio poético de Ovidio, ajustándose al canon estilistico del epilion que le impone sus propias normas, ha logrado coherencia compositiva que revelan un minucioso trabajo artístico formal, pero también un amplio conocimiento del acervo mítico.

En Ovidio, el origen de la mutación es la condena de Júpiter por su depravación e impiedad. El comportamiento de Licaón-hombre no difiere del de Licaón-lobo. Muda su aspecto de hombre a lobo, pero sus actitudes y algunos rasgos fisicos denotan su antigua fiereza: "Colligit os rabiem solitaeque cupidine caedis / Utitur in pecudes et nunc quoque sanguine gaudet (La rabia de su alma se acumula en su boca y ejerce sobre el ganado su habitual avidez de matanza, aun ahora sigue gozándose en la sangre, vs. 234-5).

La metamorfosis es formal, porque la esencia permanece, Licaón es el paradigma de la bestialidad humana. La desviación de la norma debe ser castigada.

En el Satiricón de Petronio, entre la miscelánea del entretejido discursivo de la Cena Trimalchionis, surge el entretenimiento de la narración de anécdotas y cuentos fantásticos terrorificos de raigambre popular y tradicional, cuentos breves de factura independiente. Ubicamos aqui el relato del hombre-lobo (caps.LXI y LXII).

En estos capitulos, un liberto, Nicerote, cuenta lo que a él mismo le sucedió. Afirma que vio a un soldado, huésped suyo ocasional, transformarse en lobo en un cementerio, una noche cuando la luna brillaba con todo su esplendor. Aterrado, llega a la casa de su amada Melisa quien le refiere que momentos antes habia entrado al corral un lobo que con safra carnicera habia matado al ganado, pero que el animal había huido herido por una lanza en el cuello.

Nicerote sospecha que ese lobo es su companiero y, despavorido, vuelve a su casa donde encuentra al soldado que está siendo atendido por un médico que le cura el cuello sangrante. Confirma así sus temores y se aparta horrorizado del licántropo.

El relator es Nicerote, un liberto, que manifiesta aprensión de contar la anécdota por el miedo social a ser rechazado por ignorante. El hombre educado no es supersticioso: "etsi timeo istos scolasticos, ne me rideant. Viderint: narrabo tamen" (aunque tengo miedo que estos sabihondos se rian de mi. Allá ellos: con todo voy a narrar mi historia, LXI,4).

Este recelo de Nicerote revela que su creencia en el licántropo tiene un origen popular, repudiada por la gente culta. Idea afirmada por la parodia de la formula del poema heroico, un verso de Virgilio (En. II, 729): Haec ubi dicta dedit, después de que hubo dicho estas cosas, continúa el narrador de la obra, talem fabulam exorsus est, comenzó esta leyenda, LXI,5. Aun más, el cuento de Nicerote está interrumpido por su apelación a los oyentes a los que persuade a creerle: "Nolite me locare putare; ut mentiar, nullius patrimonium tanti facio" punto, LXII,6).

(No penséis que bromeo, ningún bien valdría tanto como para que mintiera en este

Termina su relato con la misma exhortación: "Viderint quid de hoc alii exopinissent; ego si mentior, genios uestros iratos habeam" (Que otro vean qué piensan de esto, si miento, que vuestros genios tutelares me sean hostiles, LXII ,14). señalaremos:

Del análisis de los elementos referenciales de la matriz narrativa hombre-lobo

A) La Morfología de la transformación: Aquí juegan una serie de elementos rituales y mágicos que perduran hasta en los relatos actuales: la medianoche, la luna, especialmente el plenilunio, los cementerios, el contacto con material de desecho, la materia fecal, la orina, el círculo mágico: Por ejemplo, los modos de transfiguración (se desnuda, defeca entre las lápidas, 
orina alrededor de su ropa), la modalidad de conjuro (el uso de la espada) y el regreso a la forma humana: el soldado recobra su fisonomía humana con el día y la herida hecha al animal se encuentra en la persona, siendo éste el medio de identificar al uersipellis.

B) La comunidad ante el fenómeno: El efecto de la recepción del fenómeno es lo que más destaca el relato petroniano: el miedo que provoca todo hecho que se aparta del comportamiento normal de la sociedad, y el rechazo al anómalo hombre-bestia. Pavor y repudio experimenta el relator, testigo de la transfiguración, los mismos sentimientos que manifiestan los convidados a la cena, oyentes de la anécdota.

Como en Ovidio, encontramos aquí el mismo patrón mítico-ritual de la metamorfosis zoomórfica, pero en un contexto totalmente diferente. En el Satiricón, donde se imbrican relatos folclóricos basados en supersticiones ampliamente difundidas, es más evidente la emergencia del hipotexto de la oralidad.

\section{La leyenda del hombre lobo en cuentos argentinos contemporáneos: tradición y creación}

La pervivencia de la creencia licantrópica, ha logrado arraigarse gracias a la combinación de creencias europeas implantadas y un sustrato autóctono fértil y mantenerse en nuestro país. Por ello, no es de extrantar que la narrativa nacional haya incluido en sus páginas relatos literarios que retoman el mito de las más variadas maneras, que van desde las más cercanas a la tradición oral hasta la más elaborada ficción.

La escritora María Amalia Casco Encinas presenta en su obra una propuesta próxima a los relatos orales ya que inicia el cuento titulado El lobizón con la voz de Silverio, el narrador de cuentos tan viejos como él y como el mundo, relatando una creencia. Silverio es presentado como un diestro cuentista que combina hábilmente dos elementos fundamentales que no pueden obviarse en cualquier relato que incluya elementos fantásticos: misterio y terror. El narrador los llama cuentos es decir que los presenta como una ficción que no hace más que transcribir en tanto que Silverio inicia la narración con la forma típica de los relatos orales " $Y$ hoy le toca al Lobisón, ese perro grande con ojos como brasas". La historia se une a otras tantas entre las que se encuentran el Pombero, el Curupi Inmortal, el Berrador, el Yací Yateré.

Los hechos se sitúan en la provincia de Misiones, cerca de Itacaruaré. Los protagonistas son un joven matrimonio y un vecino brasileño, Antonio de Avila, quien los visita algunas noches en la solitaria vivienda, un rancho de adobe levantado en medio del monte. La pareja es brevemente descripta "el hombre pocas veces salia; la mujer, guapa y hacendosa era una perfecta ama de casa".

Precisamente el brasileño es quien, en conversaciones casuales, pone a la pareja en alerta sobre las últimas apariciones del lobisón ya que él lo había visto "con sus propios ojos" no hacía dos semanas y les comenta sus rasgos físicos y conducta: especie de perro gigante, de pelaje negro y ojos relucientes como brasas; ataca tanto a hombres como a animales; aparece los viernes a las doce de la noche, en noches de luna llena.

En oposición, la joven esposa desacredita la creencia y, en su rechazo, presenta otra característica: séptimo hijo varón de una familia sin mujeres. Las palabras de la joven revelan, por un lado, el conocimiento, hasta en aquellos que niegan la existencia de los hombres-lobo y la extensión de la leyenda, tanto en nuestra región como en Brasil; y, asimismo, la atribución a otros, indefinidos (-dicen- afirma la muchacha) la difusión y la aceptación de la creencia. En este sentido la joven representa el arquetipo de la mujer que no cree en esas historias. 
En el desenlace queda develado que es el propio marido de la joven quien se transforma en lobisón; llega incluso a atacarla una noche cuando él habia ido, bajo la luna llena de agosto, a un almacén donde solían tener lugar reuniones de juego y caña.

A la mañana siguiente, cuando lo despierta para contarle lo sucedido durante su ausencia, descubre la verdad ignorada a partir del hallazgo de un signo del ataque: las hilachas de su vestido entre los dientes de su esposo. Este elemento de reconocimiento se presenta como una prueba irrefutable con la cual finaliza el cuento.

Thay Morgenstern elabora el cuento La hilacha con los mismos elementos que el texto de Casco Encinas: la noche de agosto, la joven que desconoce que su marido es un lobisón, la sef́al de reconocimiento. En este caso, el elemento de identificación es el título del cuento.

El narrador describe, en los primeros párrafos, un atardecer de agosto antes de la tormenta de Santa Rosa. Los personajes son brevemente descriptos: obrajeros, hijos y nietos de otros obrajeros, herederos del trabajo y de la secular pobreza. El calor, la pesadez, la humedad y el silencio de la tarde constituyen el marco del relato.

Después del agobiante día y ante la inminente llegada de la noche Ramona Leites insiste a su compantero Itaricio Olivera para volver a su casa. El narrador comenta los motivos de su insistencia "era viernes y pronto interrumpiría en el firmamento la luna llena". Juan Rodríguez, el dueño de casa, se burla de sus temores y su mujer Justina Pereyra lo reprende a la vez que se persigna $y$, alzando a su hijo en brazos, un niffo semidesnudo y desnutrido, se prepara para acompanarar a los visitantes hasta un cruce del camino.

Durante la marcha hombres y mujeres caminan separados, los primeros, envueltos en silencio, las segundas, preocupadas por la tormenta que acecha y sobre todo por la luna llena: conversan sobre la necesidad de tener ramos bendecidos para encenderlos y pedir a Dios protección. El narrador plantea, desde el principio, la relación entre la religión y la leyenda, ya que los personajes confian en el poder de la oración y de elementos sagrados como armas efectivas contra un posible ataque.

Antes de la bifurcación del camino Juan se aparta un poco y anuncia a los demás que sigan. Al ingresar al monte por un angosto sendero, los personajes sienten la presencia de algo que los acecha e intentan alcanzar, a toda carrera, la salida del monte. Sin embargo, el animal los ataca y el narrador describe, con angustiosas palabras, los intentos de Justina por salvar a su hijo de las garras del animal.

El machete de Olivera resulta inútil y como último recurso para concluir con aquella pesadilla, Justina se pone a rezar el Padrenuestro en voz alta. Ramona y Olivera también lo hacen. Sorpresivamente la bestia contiene el ataque y se aleja del lugar.

El narrador no describe el aspecto físico del lobisón, pero sí su conducta: marchaba dentro del monte, acompafiándolos, acechándolos, respiraba con dificultad, gruffía, avanzaba cada vez con mayor violencia; por otra parte los golpes del machete no le causaban heridas, por el contrario lo enfurecían aún más y atacaba con mayor salvajismo en su intento por arrebatar la criatura. Estos datos presentan al lobisón como un representante del mal, bestia que persigue, observa y ataca a su presa. Los portadores de la creencia son obrajeros descriptos como victimas de la explotación y la pobreza.

A la mañana siguiente Justina y el niño emprenden el regreso a su casa en donde encuentran a Juan. Enojada, lo reprende por su ausencia y le cuenta, todavia con angustia, 10 sucedido la noche anterior. Le solicita que cuide al nino mientras ella se cambia el vestido, testimonio del ataque, ya que había sido desgarrado en varias partes. Entonces, dos indicios 
seffalan a Juan como lobisón: el llanto del niño convertido en alarido al escuchar la risa del padre y los hilos rojos, iguales a su vestido, entre sus dientes.

Los cuentos de María Amalia Casco Encinas y They Morgenstern rescatan la tradición popular en forma de cuentos en los que el abrupto desenlace constituye el elemento esencial de la trama. Además, el licántropo, en su forma humana, no posee características fisicas que permitan identificarlo como lobisón. La ficcionalización del mito, en ambos casos, apuesta a la cercanía con el relato oral a la vez que refiere con gran semejanza, según Alfredo Schroeder, una variante de la leyenda muy arraigada en el imaginario misionero ${ }^{6}$.

Los cuentos de Justo P. Sáez y Diego Angelino destacan el valor de la figura paterna como protectora de los hijos rechazados por la sociedad, aunque ambas historias concluyen de manera diferente.

Justo P. Sáenz inicia el relato Lobizones reproduciendo una conversación sostenida entre la cocinera y Aróstegui, el duef́o del campo. Este último había decidido establecer contacto con el personal ya que se había hecho cargo del campo, al norte de Entre Ríos, hacia poco y le resultaba un medio totalmente desconocido. Con esa intención empieza a frecuentar la gran cocina y all se entera del gran número de supersticiones y creencias que amargan la vida del paisanaje. Escucha hablar de las casas asombradas, del árbol que arde, de la mujer de blanco, del lobisón. Este último relato logra interesarle, ya que había heredado una infinidad de perros que vagaban famélicos por los alrededores.

Tras ese diálogo, el patrón decide ejecutar a cuanto perro pase por sus dominios para poner punto final a los molestos animales, pero más que nada a las charlas y aguerías con que sus peones estaban distraídos. Una mañana temprano y sin muchos miramientos, acaba con toda la jauria, sin saber que este hecho resulta el desencadenante de un suceso inesperado: el encuentro con don Heraclio Toledo, un estanciero criollo, sumamente retraído y díscolo de carácter, de ademanes graves y autoritarios y de lenguaje marcadamente rural.

Tal como obliga la costumbre, lo invita a comer, a pesar de no mediar entre ellos amistad alguna. Transcurrido el momento de la cena, después de pronunciados silencios, el visitante revela el motivo de su visita ante un Aróstegui fastidiado: atribulado y nervioso, le pide al duefio de casa que no prosiga con su cacería y que si una noche llega a divisar a un perro negro, muy orejudo y grandote rebuscando la basura que no lo mate. El pedido es interrumpido por un furioso ladrar de perros que estalla afuera. La entrecortada voz del vecino, que acaba su petición, contrasta con sus ademanes graves y autoritarios. Entonces, la criada anuncia desesperada que se trata del lobisón y Aróstegui, tomando el winchester de la alacena, se planta de un salto en el corredor y ve en la oscuridad, a veinte metros de la casa, algo como un gran ternero negro de ojos fosforescentes que tenía a raya a la jauría.

Cuando está por disparar una fuerza poderosa le arranca el arma de las manos al tiempo que su vecino le grita: “-¡No tire, señor, no tire! ¡Es él! ¡Es él! ¡El lobizón! ¡Mi hijo!”. Toledo ante los hechos, completa la razón de su pedido y revela el verdadero motivo de la visita y la causa de su extranio encierro y conducta poco habitual. El abrupto final, al igual que en los textos anteriores, es el eje sobre el cual se construye la trama.

De las características básicas de la creencia, se hace referencia al aspecto físico: se trata de un perro negro, casi tan grande como un ternero y de ojos brillantes y a la condición, probable, de séptimo hijo varón, aunque no se especifica que corresponda a una serie

\footnotetext{
${ }^{6}$ Schroeder, Alfredo, op.cit. p. 218-219
} 
ininterrumpida, ya que Heraclio Toledo tiene también tres hijas mujeres. De su conducta, se sefiala que su manjar predilecto son los niños sin bautizar y que rebusca en la basura, que ataca a los perros a los que ahuyenta con el ruido que producen sus orejas, dato presente también en la versión de Bayona, aunque poco conocido en los relatos orales. Por otra parte, el licántropo no participa como personaje. El relato se centra en la actitud del padre, quien, en un intento por defender a su hijo de la muerte, sale de su encierro y, contra lo acostumbrado, dado su carácter severo y autoritario, ruega a Aróstegui que no siga con la matanza de los perros.

Los portadores de la creencia son la cocinera, calificada de "entrerriana idiota", de tal modo que pesa sobre ella un estigma de marginal y esa condición hace inverosimil su relato, al menos para su patrón, no así para la peonada; y Toledo, sobre quien recae la maldición.

Aróstegui, el dueño del campo (representa a otra clase social, opuesta a don Heraclio, único estanciero que no tiene "For", antiguo en todo, en sus modales, vestimenta e incluso en la posesión de la propiedad), no se muestra como un ser supersticioso o temeroso, pero es consciente de que los comentarios de la mujer pueden desencadenar el miedo. Esas aglerias, ante un público fácilmente influenciable, lo obligan en dos ocasiones a disparar su arma como modo de eliminar la causa del pánico. En este sentido, representa el extranjero que, llegado a una tierra desconocida, descree las historias del lugar hasta que se enfrenta con los hechos.

El escritor Diego Angelino, al igual que Justo P. Sáenz, destaca la actitud del padre quien para proteger a su hijo decide sacrificarlo él mismo. Tras la lectura del sugestivo título, Antes de que amanezca, la voz del narrador cuenta la historia de la familia Álvarez, a partir del nacimiento del hijo menor. Con marcada insistencia esa voz se transforma en una crítica a la decisión de los Álvarez de traer al mundo (Campo del Banco) a un séptimo hijo varón, sabiendo el inexorable destino que le está reservado. El narrador presenta como argumentos: "seis hijos varones habian tenido los Alvarez y debieron quedarse conformes", "él, más que nadie, sabia que si era varón el séptimo estaba condenado por el destino".

Tras el alumbramiento, toda la comunidad se convulsiona: la creencia mítica tiene gran raigambre al punto de que no es posible una excepción. Unos meses después comienzan a sucederse los hechos que, en cierto modo, todos esperaban: entre copas la gente murmura que anda una forma negra rodando la laguna. A partir de ese día el imaginario colectivo revela una serie de apariciones: unos afirman haber visto a chancho y otros un zorro guará, pero más grande todavía. Las visiones son tema habitual de conversación a espaldas de los Álvarez.

El séptimo hijo comprende tempranamente el miedo social respecto de su condición y termina por acostumbrase al mutismo que lo rodea e incluso llega a necesitarlo. El narrador testimonia el castigo social al que se ve sometido el joven.

Una noche, sin saber por qué, decide salir de su casa bajo el amparo de la luna. Esa incursión le permite descubrir que la noche también tiene su voz y sumergirse en un diálogo silencioso, reparar en las imágenes nocturnas y finalmente darse cuenta de que por fin no está solo. Esa experiencia logra despertar sus instintos y comienza a cumplir el fatídico ciclo que se inicia con la luna crecida y culmina antes de que amanezca. El cambio no pasa inadvertido para el padre: ahora es el viejo Álvarez quien abandona sus hábitos y se dedica a seguir a su hijo.

Una doble transformación se ha operado: el hijo menor marcha hacia su destino y su progenitor comprende que ha llegado el momento de hacer frente a su capricho y su obstinación frente a la designios de la naturaleza (según la creencia generalizada y por él compartida). Para terminar con la tragedia familiar, de manera violenta, pero paradójicamente a modo de alivio, decide poner fin a la vida de su hijo "Porque él no quería saber si era chancho o guará, no 
hubiera \$oportado saberlo. Levantó el revólver y dijo antes de que amanezca. Para que no sufra".

El cuento denuncia la actitud de quienes, movidos por una creencia, obligan a los estigmatizados a autocumplir el destino que se cree tienen reservado. De esta actitud surgio la necesidad de crear un rito de sustitución, el padrinazgo presidencial, para frenar la exclusión y la eliminación de personas consideradas injustamente monstruosas.

En este caso, no resulta significativa la morfología del lobisón como la recreación del previsible destino al que se enfrentan quienes deciden cruzar los límites de la naturaleza. Por ello, el texto presenta una severa critica contra la sociedad que excluye y elimina al otro, a la vez que identifica la bestialidad no con el joven sino con aquellos que buscan eliminarlo.

Escrito en la segunda década del siglo XX, el cuento El lobizón de Bayona, junto con el de homónimo de Horacio Quiroga, es una de las más antiguas recreaciones literarias.

El relato comienza reproduciendo el diálogo entre Catalina y su madre, dona Eduvigis Segarra, con los giros y expresiones del habla rural. La conversación se centra en la aparición del lobisón. Su madre no cree en sus palabras al punto de tildar a su propia hija de agorera supersticiosa. La joven, a pesar de todo, ratifica sus dichos y cita la experiencia de las hermanas Rojas. Pero ni siquiera esta alusión hace cambiar de parecer a su madre.

El escenario se ubica en el rancho de Dofia Eduvigis, mujer mayor descripta siguiendo el paradigma de anciana-curandera-charlatana, cuyo mayor atractivo son sus hijas, razón por la cual la gente del pueblo concurre a su casa. Allí un triángulo amoroso comienza a tejerse entre Miguel Tello y Luis Guzmán, los pretendientes de Rosa, una de sus hijas.

Presentados como opuestos, el primero es un paisanito honesto y trabajador con quien la joven está comprometida; el segundo es un estudiante de medicina, de vacaciones en la estancia de sus padres, de mirada penetrante, sonrisa burlona y aire de mozo bien que lo hacen un tipo distinguido, pero raro a la vez.

Un cruce de miradas entre Rosa y Luis es suficiente para que al joven se le despierten sospechas. En vez de precipitarse, opta por llevar a cabo un plan de observación: estudia los comentarios y gestos de su prometida con la esperanza de despejar o confirmar sus temores.

Cierta noche escucha atónito que Luis cita a Rosa a las doce en el jagllel. Ante la inminencia de los hechos se retira de la casa de su prometida y mantiene una vigilancia infructuosa. Al día siguiente repite el seguimiento y una situación desconcertante se presenta ante él: en un pequeño sauzal ve una forma rara, de persona o de animal, que se mueve de un lado a otro. Al rato Rosa se reúne con esa especie de oso dispuesta a huir en un auto que los espera. Sin dudarlo, el prometido logra atrapar al raptor y rescatar a la joven. Victima y victimario son llevado ante Eduvigis. La hija suplica perdón a su madre y el héroe hace lo propio con Dios.

Son exiguos los detalles que se incluyen en el relato referido al aspecto exterior de este animal: sólo se menciona que es un hombre perro y Miguel lo relaciona con un oso. Respecto de su conducta, se sef̂ala que se llevó en cierta ocasión a Tránsito Rojas, otra joven del lugar. Asimismo, Rosa acepta huir con el lobisón quien, en este caso, tiene marcadas connotaciones eróticas pues sus victimas son mujeres jóvenes a quienes seduce y obnubila.

En cuanto a los portadores de la creencia: la vieja curandera, contrariamente a los otros cuentos analizados, no cree en la leyenda, no así su hija quien afirma haberlo visto. El autor cambia el estrato social habitual del lobisón, ya que en general se adjudica la creencia a las 
clases inferiores. Por el contrario, en este cuento resulta lobisón un joven estudiante de medicina.

Horacio Quiroga en El lobizón relata la historia de un grupo de personas reunidas en el patio de una estancia. Las señales espaciales y temporales son reducidas a su mínima expresión: una noche de luna en un campo indeterminado.

De repente un grufido altera la calma y los perros son los primeros en mostrarse alertas. Casacuberta, el anfitrión, le quita dramatismo a la situación. Pero un segundo grufido desencadena la acción tanto de los perros como de las personas: los animales protagonizan una lucha contra un animal extrafio y los hombres se movilizan hasta el lugar (las cercanías de un solitario ombú). Finalmente uno de los personajes, Vivas, dispara y da muerte al animal.

Superado el episodio, y en un intento por encontrar una explicación a los hechos acontecidos, Vivas cuenta a los presentes una historia, referida por el narrador del cuento: el primer grufiido del perro, fue para él desencadenante de un recuerdo, al que presentía como probable explicación de lo ocurrido esa noche. Con todo, no se habfa atrevido a comentarlo antes porque "era una idea estúpida". De esta manera inicia un relato enmarcado que constituye el verdadero nudo de la historia. En este segundo relato están presentes los elementos indicadores del espacio (estancia del Uruguay, al norte) y tiempo (marzo y abril) que aportan una mayor verosimilitud a la narración.

Vivas se había mudado temporalmente a una estancia uruguaya. Alli estableció relaciones con los peones, quienes a su vez le contaron que otro peón, Gabino, era lobisón: sus caracteristicas fisicas asi lo justificaban. Entre Vivas y Gabino surge una relación en la que este último acepta las bromas y chanzas de su patrón respecto de su condición de lobisón. Sin embargo, un peón indeterminado le advierte acerca de su ingenuidad.

Al mes, Gabino invita a Vivas a su casamiento. La novia conoce los comentarios acerca de su futuro marido, pero no cree en ellos, al igual que su familia. Durante la noche de bodas, todos hacen chanzas sobre el comentario popular. Luego de retirados los novios, un alarido de terror proviene de su habitación. Al entrar se encuentran con un chancho enorme en la misma cama en la que está desmayada la recién casada. El animal, tras mantener durante unos segundos una mirada de rabia y rencor dirigida hacia Vivas, huye perseguido por los perros.

El relato referido finaliza con un intento de explicación racional: cabrfa la posibilidad de que un chancho perdido hubiera asustado a la mujer, mientras Gabino se ausentaba por un momento. Aunque finalmente Gabino desaparece para siempre. Al final del relato Vivas reconoce que toda esa historia ocurrida en el Uruguay, lo turbó por completo tras lo ocurrido y concluye su narración resaltando un detalle, "el animal de esta noche, no gruñó ni gritó una sola vez". Este final abierto sugiere que podría ser el mismo animal el que, en dos momentos y lugares diferentes, se presenta ante el mismo testigo: Vivas. Justifican esta posibilidad el comportamiento similar del animal en las dos ocasiones y el odio con que Gabino-lobisón había mirado a Vivas la noche de su boda.

Los datos sobre la morfología de la transformación son más bien escuetos. En el primer relato, un chancho, tras un disparo, es sacrificado. En principio no se aclara que sea lobisón pero la concurrencia de ciertos elementos y el posterior relato de Vivas contribuyen a identificarlo con el lobisón. En el relato de Vivas se hace alusión a las consabidas características de este ser legendario: alto, amarillo y flaco, adjetivos aplicados a la fisonomía de Gabino. Hacia el final del relato, se hace referencia a un chancho enorme, de pelo erizado y 
belfos retraídos que ataca a la novia en su lecho. La aproximación de los hechos sucedidos en la noche de bodas por un lado, con la creencia general de que Gabino era el hombre-lobo, por el otro, le dan el marco necesario para llegar a la interpretación de que ese personaje es el lobisón.

En cuanto a la reacción de la comunidad, es válido pensar que el narrador no conoce la leyenda hasta que escucha el relato de Vivas. Éste sí la conocía pero decide contarla recién cuando las circunstancias prácticamente lo convencen de hacerlo. Cierta frase aislada, " $m i$ facha urbana", se convierte en indicador de la condición social de Vivas. Cuando los peones (pertenecientes a un nivel social inferior al del patrón) le cuentan sus sospechas y creencias (ellos sí toman en serio la leyenda), él responde con bromas al respecto, aunque ya conocía la leyenda del lobisón invisible. Sólo cuando vivencia los hechos su pensamiento se revierte. Por su parte, Casacuberta, el anfitrión, no se siente intimidado por el relato popular. Respecto de la hipótesis extendida de que las leyendas se arraigan en los niveles menos cultos, la familia de la novia es una excepción puesto que le resta importancia a la leyenda.

Los textos de Quiroga y Justo P. Sáez oponen los lugareños creyentes al extranjero incrédulo, a la vez que remarcan la dificil relación entre patrones y peones.

Ricardo Róos Ortiz en Un lobizón en los fortines relata la supuesta aparición de un lobisón en el marco de la Conquista del Gran Chaco. Este escenario otorga al cuento caracteristicas especiales puesto que, en una situación de enfrentamiento, el mestizo 0 indio resulta un doble enemigo, por una lado como nativo salvaje y por otro como bestia: el lobisón.

El cuento se organiza en tres parágrafos. En el primero un narrador omnisciente describe el fortín y el lugar en el que se reúnen, a la tardecita, los milicos a tomar mate. Luego, en estilo directo transcribe las conversaciones mantenidas entre Higinio Fierro y otros miembros de la milicia a la hora del fogón. El tema del diálogo es la presunta transformación del soldado Iribarne en lobisón. El rumor, que circulaba en el fortín, es -para el narradorazuzado por la credulidad criolla. Así, la leyenda es presentada, por un lado, como una creencia aceptada fácilmente por los nativos $y$, por otro, como una respuesta del hombre frente a lo desconocido.

La lectura del diálogo permite detectar ciertos elementos de la morfología de la transformación: la metamorfosis se produce en las noches de luna llena, es el séptimo hijo varón, se transforma en perro y no muere. A su vez, el soldado al que se considera lobisón es un indio toba, cuando menos un mestizo.

Uno de los asistentes, el Cabo, no está de acuerdo, pero por más que se esfuerza en negar la posibilidad de tales rumores, la fama de Iribarne es generalizada. Entonces, el más viejo, presentado como autoridad, refuerza y arraiga la creencia en la milicia, aunque no seffala a Iribarne como lobisón tampoco niega la posibilidad de que lo sea.

En el parágrafo II, un disparo causa revuelo entre los soldados. Un centinela, Cirilo Urrutia es atacado por un animal que asocia con un aguará-guazú. El resto de los soldados, por el contrario, afirma que se trata del lobisón y demanda la presencia de Iribarne.

Éste desmiente las acusaciones, afirmando que no es lobisón ni séptimo hijo varón, pero decide desertar puesto que no confia en que le hayan creido: sabe que es víctima de la sospecha colectiva, que es observado, señalado y rechazado y termina comportándose como se espera que lo haga. En el texto aparece la acción colectiva: la voz de alguno, la voz sin rostro, alzándose del grupo y sefialando el curso de las acciones. En este sentido, la comunidad por una parte, crea y fomenta la creencia sobre la transformación de un hombre en lobo y, por otro, aparta al seffalado o busca su eliminación. 
En el parágrafo III se produce un salto temporal; estimado en varios afios. Se afianza la conquista del Chaco y el escenario de la historia es otro, la consolidación de la Conquista: Francisco, un cacique toba, había cobrado renombre por su astucia y audacia. Éste y otros respondian al llamado de los jefes militares y concurrian al sitio convenido para un acuerdo. La sola presencia de tantos nativo es considerada por el narrador como un triunfo.

Una charla ocasional recuerda al comandante el soldado fugitivo. Iribarne, sintiéndose reconocido, niega nuevamente las acusaciones de las que alguna vez fue víctima y el comandante decide guardar el secreto puesto que ese develamiento podría costar la paz. De esta manera es el lector quien tiene que completar el relato y juzgar la importancia de la transmisión de un rumor cuando los intereses responden a una causa mayor.

En Fases de la Luna, de Sara Gallardo, se narra el enfrentamiento de un sacerdote con un lobisón. Los primeros párrafos presentan el encuentro entre el padre Matías (representante de la cultura europea asociada con la institución cristiana) con la barbarie de la pampa (representada por las vastas extensiones, la soledad, el silencio). Este cura católico, nacido en Alemania y procedente de Paraguay, recorre la pampa para bautizar, casar, confesar, convertir a la religión a los nativos. Tras un penoso viaje a caballo llega a la pulpería El Retoño, donde son requeridos sus servicios sacerdotales, puesto que habían encontrado muerto a un vasco criador de ovejas. La expresión de terror en la cara del muerto y la herida que tenía en la garganta llaman su atención. Aunque pregunta, nadie le explica la causa de la muerte.

En vistas de lo oido en confesiones decide alterar el rumbo de su itinerario, puesto que "donde está el mal debe llevar el bien".

Emprende entonces solo el viaje hasta que mete el pie en un hoyo y se recalca el tobillo. El desafortunado accidente lo pone en contacto con un grupo de jinetes que lo rescatan $y$ le ofrecen asilo.

Durante un mes comparte su convalecencia con esa familia. Trece eran los hijos de la pareja que le brinda hospitalidad, pero curiosamente, sólo el menor de ellos es descrito de forma individual: enorme, un bozo sobre el labio, mejillas exangles, muy alto y de aspecto enfermo. No despierta el aprecio del padre ni el de sus hermanos, pero si el cuidado de la madre, quien en reiteradas ocasiones pide al sacerdote que cure a su hijo. La licantropia es, para la madre, una enfermedad que puede ser curada.

Las fases de la luna se suceden y agitan a la madre del muchacho y, en vista de una nueva proximidad de luna llena, insiste en su ruego al sacerdote, quien aceptando el desafio de curar al joven, intenta una nueva alternativa de sanación: esta vez propone una cabalgata como terapia. Se dirigen, entonces, a un arroyo donde pasan unas horas. Durante el regreso se cumple un hecho fatídico: un mes después de la muerte del vasco, bajo la misma luna llena tiene lugar la transformación del joven que ataca al sacerdote con inusitada violencia. En el fragor de la lucha se oye el disparo mortal del padre del muchacho. Moribundo, el joven, pide al cura que lo bautice para romper el hechizo. El religioso: "lo hizo con la sangre que recogió en la mano. Vio la sonrisa que habia esperado tanto. Vio la expresión de dicha". El sacerdote comprende que ese niño, signado por el destino, es una víctima de la fatalidad, de una maldición que destroza su vida y la de los demás.

El poder religioso surge como el de mayor primacía para lograr la eficacia en la cura. A partir de la simbología cristiana, asumida desde una posición de lucha entre el bien y el mal la bestialización es sinónimo de salvajismo, de degradación humana. Las características del personaje revelan que, como niño ha perdido la fuerza vital, es un desecho humano, como 
animal se aproxima a la monstruosidad. Por otra parte, aparece sólo a través de los ojos de la voz narrativa, no se explica nunca lo que siente, sólo se ofrecen indicios externos que permiten reconstruir lo que sucede en su interior: "sonreía como un idiota, una lágrima le corría, los párpados del joven temblaban, esbozaba una sonrisa", ante la cual el cura contiene las ganas de llorar y encuentra el indicio de un alma sumergida en el dolor.

Ambos personajes, tanto el sacerdote como el muchacho, son seres solitarios, aislados. Sus destinos fatales representan la dificultad, pero no la imposibilidad, de catequizar esa pampa hostil, desértica, salvaje.

Al final del relato el narrador anuncia la muerte del catequista no por las heridas y el ataque sino por la satisfacción del bien cumplido, por la obtención de la sonrisa del nifio que representa una recompensa, una liberación y, en definitiva, un triunfo. La fuerza del instinto animal, la ternura, la violencia, la procreación y la muerte giran en torno a los personajes para condenarlos y, finalmente, liberarlos.

De la estructura básica de la leyenda, están presenten la condición de séptimo hijo varón, el aspecto demacrado y el comportamiento reservado del joven previos a la transformación, la metamorfosis durante el plenilunio, la fiereza del ataque, la analogfa con un oso (de acuerdo con la nacionalidad del sacerdote). En cuanto a la forma de eliminación, el lobisón muere herido por un arma de fuego. El bautismo como elemento eliminador de la condición bestial, se suscita en el último momento.

Enmarcado en un verano impreciso, el cuento El lobisón de Horacio Riveros Sosa relata una pasión desbordante, casi salvaje, que se transforma en serenidad y juicio gracias a la supuesta presencia de un lobisón. El escenario de este desborde es una estancia alejada, sin mayores certezas acerca de su ubicación.

La vida de Valentín, el protagonista, transcurre monótona, en medio del campo, procurando dinero para la construcción de su rancho. Una tarde, de manera inesperada, se presenta Gregoria, la joven hija de un puestero del lugar, cuya presencia le enciende la sangre como ninguna, aunque había visto muchas andando por pueblos y chacras.

El diálogo gira en torno a preguntas de rigor hasta que Valentín sefiala que entre ellos había quedado una respuesta pendiente: Gregoria debía confesar si estaba dispuesta a corresponder a los requerimientos amorosos del joven peón. Sin embargo, prefiere sembrar una duda y afirma que debe pensar primero en otras cosas más importantes. Esta negativa despierta unos celos incontrolables en Valentín quien insiste en visitarla esa misma tarde, propuesta que la joven rechaza por temor a las habladurias, mientras emprende el regreso a su casa.

No obstante la negativa Valentín se prepara para verla. Una vez acicalado se dirige a la cocina mudo, malhumorado por su impaciencia y su indecision, pues no acierta con un pretexto que lo justifique ante quien le inquiriera algo. La cocinera, al advertir su presencia, comienza a preguntar sobre su próxima salida, pero la impaciencia del protagonista hace que sus repuestas sean hoscas y evasivas. Sin embargo, la mujer descubre su intención y lo exhorta a que postergue la visita argumentando que quiere aprovecharse de la muchacha porque está sola y lo amenaza con contarle al patrón.

Totalmente fuera de sí, Valentín grita exasperado, dejando ver sus propósitos inconfesables: "-jVieja charlatanai iNij la policia será capaz de atajarme esta noche! jAntes que el patrón me la quite le voy a poner mi marca a esa potranca! ...". Para remarcar sus dichos saca el cuchillo y da un golpe en la mesa. Sin embargo, un silencio expectante y un doliente aullido, de lobisón según la cocinera, lo paralizan y esfuman su ardor varonil. 
Más molesto que antes, decide refugiarse en el cobertizo, sumido en la oscuridad. Un olor nauseabundo impregna todo el lugar obligándolo a permanecer alli. Entre sueños, recuerda haber ofdo durante su nifiez, casos referidos sobre el lobison. Realidad y fantasfa se mezclan en su mente. Los recuerdos de la infancia se confunden con los temores del presente.

Repentinamente la bulla cesa con la llegada de Don Goyo, padre de Gregoria, ausente de su casa debido a los problemas de salud de su mujer. El anciano le confiesa haber sentido en horas de la noche, mientras regresaba, cierta sensación de presagio negativo respecto de sus hijas: el anuncio de una amenaza. Para calmarlo, Valentín le resta importancia a su angustia y afirma que esas cosas suelen pensar los padres cuando están lejos de los hijos. Sin embargo, en su interior, esa confesión le produce tal remordimiento que, luego de despedirse, resuelve ir a pedir la mano de Gregoria "como Dios manda".

La supuesta presencia del lobisón (su aullido es reconocido como tal pero la oscuridad de la noche y su refugio en el cobertizo crean dudas sobre su paso por el lugar; además bien puede tratarse de un ardid de la cocinera para proteger a su ahijada) y el encuentro con Don Goyo provocan en el protagonista un cambio interior: las turbulencias de una pasión correspondida a medias ceden paso al dominio de todas sus facultades.

Una lucha en el interior de Valentín se desata a causa de sus deseos, que la impaciencia casi bestializan, y las palabras profundas y conmovedoras de un hombre mayor logran, finalmente, despertar el juicio y la razón en él.

Como si sus sentimientos hubiesen conformado un círculo, ese muchacho trabajador, alejado de las tentaciones como bailes, carreras, pulperías y otras amenidades, que sólo pensaba en ahorrar y había comenzado a hacer su rancho, es arrastrado al salvajismo por la experiencia de un sentimiento apasionado que lo confunde y altera al punto de sacarlo fuera de si, para luego retomar su equilibrio inicial.

Acerca de los elementos referenciales de la matriz narrativa hombre-lobo es interesante observar, en principio, los referidos a la metamorfosis: si bien ni Valentín ni la cocinera ven al lobizón, la descripción que contiene este texto hace referencia a los recuerdos de niffez del protagonista y a los dichos que tuvo oportunidad de escuchar acerca del animal: séptimo hijo varón, se transforma en un perro grande de pelo oscuro, aparece los viernes, hace ruido con sus orejas para generar miedo, mata a los que lo identifican, come excrementos y nifios no bautizados (interferencia con la institución religiosa, sumada a la acción de santiguarse de la cocinera y a la idea de la transformación del lobisón por designio del demonio). Seres colectivos "correntinos, chaqueños paraguayos, hombres que eran muy hombres" se constituyen en portadores o difusores de la creencia, los que con sus cicatrices demostraban la veracidad de sus dichos.

Sintetizaremos los relatos de Manuel Mujica Láinez El lobizón y Enrique Anderson Imbert Licantropia. Para su análisis remitiremos a nuestro trabajo El mito del hombre lobo en la narrativa argentina?

En el primero, El Hidalgo don Pedro Esteban Dávila, gobernador del Río de la Plata, conoce a una joven mestiza que despierta en él deseos lujuriosos. Atormentado por esa pasión prepara una comedia que consiste en hacer creer a Sancho, el marido de la mestiza, que él es un lobisón. Llegado el momento, el lascivo español se encuentra en la choza con Mari-Clara.

\footnotetext{
7 En la página web de la UNNE, Comunicacions Cientificas y Tecnológicas, edición 2006, Secretaria General de Ciencia y Técnica: www.unne.edu.ar.
} 
Después de unas horas, una tempestad se desata, oyen el grito de Sancho y creen escuchar un ansioso jadear de bestia que olfatea. Don Pedro sale y la mestiza cierra la puerta dejándolo a merced de la tempestad y de la aparición del presunto lobisón. Sugestionado por la noche y el miedo, cree palpar la pelambre de la bestia. Para él ya no hay posibilidad de regreso al mundo racional y sucumbe en la pesadilla. A la madrugada le recogen unos carreteros, $y$, sin reconocer a Su Sefioria, lo arrojan sobre unos fardos de cueros malolientes.

En Licantropia el narrador, un escritor, cuenta las peripecias vividas durante un viaje en tren donde encuentra a su vecino. Esboza una irónica comparación entre la mente racional del Doctor en Ciencias Económicas, de talento especulativo, y sus propias cualidades, unidas a la imaginación. El diálogo se orienta de la economía hacia la literatura fantástica. Genovesi le ofrece anécdotas para que escribiese y se hiciera famoso. Así, las dicotomías que aparecían como propias de cada personaje se desdibujan y descubren las tensiones entre el pensamiento Iógico racional y su imposibilidad de explicar determinadas realidades. El narrador relata el final de su vivencia, el regreso a la realidad objetiva y refiere algo espeluznante: "Espantado, noté que mientras repetía 'créame, lo sé, el lobisón existe', se metamorfoseaba. Y cuando terminó vi que alli, acurrucado en su cubil, se habia convertido en un grandisimo tonto". En esa aventura salen a luz los rasgos duales de los personajes, la idea de que todo hombre tiene un doble en forma animal, dimensión desconocida de la conciencia.

Finalmente resumimos los elementos referenciales de la matriz narrativa hombre-lobo (concordantes o discordantes) con los que los autores resemantizan el mito:

Ubicacion expacio-temporal: los textos recrean diferentes momentos de la historia argentina atravesados por la misma creencia: desde la época de la catequización hasta la actualidad. El espacio geográfico es un escenario rural de provincias del noreste argentino y la pampa. La única excepción se presenta en el cuento de Anderson Imbert ambientado en una ciudad.

\section{Morfología de la transformacion:}

Comportamiento humano: en general no se describe el comportamiento del licántropo humano, como diferente de la habitual conducta de los hombres. Esto provoca que el reconocimiento sea inesperado en la mayoría de los casos y resulte una sorpresa para los otros personajes. A esta modalidad se oponen los cuentos de Sara Gallardo, Diego Angelino, Enrique Anderson Imbert y Mujica Láinez ya que en todos estos casos la fisonomía de los personajes parece llevar el sello del instinto animal.

Comportamiento animal: atacan a animales domésticos (gallinas y perros) y a personas. Algunas versiones mencionan como manjar predilecto los nifios no bautizados, hecho que revela la interferencia con el cristianismo.

Modo de transfiguracion: la metamorfosis se produce en una especie de perro gigante, de pelaje negro y ojos relucientes, o un animal extraño, mezcla de chancho y ternero. En el cuento de Ríos Ortiz es asimilado a un aguará guazú, en tanto que Bayona y Sara Gallardo lo comparan con un oso, en este último caso hay que tener en cuenta la nacionalidad del sacerdote: Alemania.

Forma de exterminio: armas de fuego, aunque no se seffala que sea necesario bendecir las balas, como es común en los relatos orales. La oración como forma de conjuro demuestra la influencia religiosa en Morgenstern y el bautismo como redención está presente en Gallardo.

Motivos de la transformación: en Mujica Láinez, Riveros Sosa y Anderson Imbert es resultado de la bestialización del hombre, en los restantes textos deriva de una maldición. 
Portadores de la creencia: en general son peones, obrajeros, mestizos, es decir, las clases más relegadas. Por el contrario los patrones, generalmente extranjeros en la zona, son presentados como cultos, educados, económicamente prósperos y sobre todo reacios a las creencias propias del lugar. Los relatos tejen oposiciones entre los lugarefios creyentes y los extranjeros incrédulos, a la vez que resaltan la dificil relación entre patrones y peones. Los portadores son caracterizados como incultos, pobres, fácilmente influenciables, supersticiosos, agoreros. Estos calificativos hacen que sus relatos sean desestimados y poco creibles. Resultan excepcionales los cuentos de Anderson Imbert (el personaje es un contador exitoso), Bayona (el joven es estudiante de medicina) y Mujica Láinez (un gobernador incrédulo que termina sugestionado por su propia creación). Los licántropos viven aislados, en ranchos apartados, alejados de la sociedad, ya sea por decisión propia o por la exclusión a la que se ven sometidos. Además, en los textos, está presente también el rumor, esa voz impersonal a la vez de todos y de nadie, que murmulla buscando la eliminación de los diferentes.

\section{Conclusiones}

La licantropia y los relatos de transformación del hombre en bestia han ido unidos a la historia y la leyenda de los pueblos y han sido interpretados como el miedo social e individual a la desviación de la norma: la posibilidad de que el hombre libere fuerzas internas irracionales que se apoderen de su raciocinio y lo lleven a un estado primitivo.

Las primeras manifestaciones literarias de emergencia de la matriz de metamorfosis zoomórfica en lobo se dan en textos grecolatinos, los que reelaboran nuevas significaciones. En el marco de un virtuosismo estético, Ovidio inserta la leyenda en un tiempo primordial, entre el mito de las edades, de la paulatina degradación del género humano y el escatológico de la destrucción de la humanidad, Licaón hombre-animal es el modelo ejemplar del salvajismo que motiva una serie de sanciones punitivas. En el episodio de la Cena, Petronio pone en juego una polifonía de voces narradoras, la voz del propio anfitrión Trimalción y la de otros invitados pertenecientes a un medio sociocultural urbano de escasa cultura, entre ellos la de Nicerote y su relato del versipellis que muestra una intención de imitar los discursos propios de esa clase social intertextualizando fuentes folclóricas. Las indicaciones de Nicerote del temor que siente a la burla de los más instruidos, nos enfrenta con el hecho de la apreciación social del fenómeno como creencias propias de la gente inculta.

En las obras argentinas, encontramos el mismo proceso de intertextualización del relato tradicional. En los relatos de Anderson Imbert, Mujica Láinez y Rivero Sosa, más elaborados a nivel simbólico, el hombre-lobo -como en Ovidio- no necesita presentarse en forma animal. Por su comportamiento, sea por su estupidez, su crueldad o instintos desatados que lo llevan a dafiar al otro, se comportan con la fiereza del animal, son semilobos. En los restantes, -como en Petronio- con distintos grados de ficcionalización, a través de las estrategias discursivas del testimonio o la del relator de cuentos, emergen en la superficie textual los relatos de la tradición oral donde perviven muchos elementos mítico-rituales: la medianoche, la luna, especialmente el plenilunio, el ataque a corrales y gallineros, el conjuro mágico. Además, como en este autor latino, casi siempre los portadores de la creencia son individuos de clases bajas desacreditadas por la clase culta. 
Los cuentos de María Amalia Casco Encinas y Thay Morgenstern rescatan la tradición oral a partir de la narración de una leyenda muy popular en la zona misionera. En este sentido, ambos textos recrean, con escasas variantes, el encuentro con un hombre lobo que es posteriormente identificado por un signo del ataque. Comparte esta caracteristica el cuento de Justo P. Sáenz quien en su obra resalta la existencia de una serie de relatos populares en la zona de Entre Ríos, con lo cual la leyenda del lobisón queda presentada, también en este caso, como una más entre tantas.

Los textos de Quiroga y Ríos Ortiz, de más elaborada ficción, centran su interés, el primero, en el relato enmarcado construido en torno a la aparición de un lobisón en dos situaciones distintas; en tanto que el segundo recrea la leyenda en el marco de la Guerra del Chaco, escenario propicio para la eliminación del otro, en este caso un mestizo.

Bayona resalta en su obra el componente sexual que suele ir unido a la leyenda, también delineado en Mujica Láinez con matices diferentes, ya que en el primero el lobisón seduce jóvenes a las que luego, evidentemente, mata; en tanto que en el segundo, el Gobernador, para gozar de los amores de una mestiza, hace creer al tosco marido que es un lobisón. El triángulo amoroso es el eje de ambos cuentos, aunque el desenlace cambia en cada caso.

Los textos de Diego Angelino y Justo P. Sáenz conmueven por el amor de los padres quienes intentan proteger a sus hijos de la barbarie. Uno busca evitar que lo maten y ruega por su vida, el otro decide, movido por la culpa y el amor, darle muerte para liberarlo de la maldición.

Los componentes simbólicos son rasgos que distancian los cuentos de Anderson Imbert, Mujica Láinez y Riveros Sosa de las otras producciones ya que cuestionan los límites entre lo racional e irracional en el hombre, las consecuencias de dejar aflorar los instintos y las fuerzas oscuras del inconsciente para dejar paso a las manifestaciones de la parte animal.

En el caso de Mujica Láinez, la novedad nace a partir del miedo que suscita en el protagonista el enfrentarse con lo desconocido. Comienza, entonces, un proceso que finaliza con una metamorfosis, expresión del inconsciente, que cobra forma a partir de su propia imaginación creadora: el cambio no es físico sino que afecta a la personalidad profunda y está presentado como castigo por su conducta social deshonesta. En el cuento de Anderson Imbert, en el "Doctor en Ciencias Económicas", hombre racional y especulativo por profesión, surge su faz irracional y oscura que lo transforma en casi un salvaje.

En el caso de Riveros Sosa, un joven es transformado, por un deseo sexual desmedido, en una bestia capaz de destruir lo que ama. Se enfrentan, en el personaje, dos polos opuestos que se excluyen mutuamente: pasión y razón. La primera deja salir a la luz el instinto sexual que lo convierte en una fuerza destructora; en tanto que la segunda lo vuelve a la calma y al reconocimiento de la armonía y el compromiso como elementos de un afecto sincero.

El horror en estos relatos no es el producto de una realidad superior a la humana sino de una inferior, que degrada al hombre y lo lleva a un estado primitivo. De este modo, la bestialización debilita en los personajes la percepción de la realidad: en ese espacio se manifiesta lo inconcebible, lo que no puede ser considerado por el pensamiento racional.

Esta característica está presente también en el texto de Angelino ya que el padre no ha comprobado que su hijo es, efectivamente, un lobisón. Por el contrario, el remordimiento y la ternura lo llevan a sacrificarlo antes de verlo bestializado. En este sentido el texto denuncia que la barbarie no está en el excluido sino en el que excluye. 
En el S. XX, el renovado interés de los discursos literarios y massmediáticos por la leyenda del lobisón devela una tendencia cultural: por una parte, de revalorización de lo folciórico, y por otra, de rebeldía contra el imperio del racionalismo y el cientificismo imperantes; y forma parte de un fenómeno más amplio: el espacio teratológico de la aparición de monstruos como expresión de la alteridad, del miedo del hombre a perder su identidad, miedo a la exclusión social, a no ser reconocido por el otro $^{8}$.

\section{Corpus}

1. El lobizón de María Amalia Casco Encinas (en Historias que no debieran ser contadas. Resistencia, Banco del Chaco, 1977)

2. La hilacha de Thay Morgenstern (en Leer la Argentina. NEA. Bs. As., Eudeba, 2005)

3. Lobizones de Justo P. Sáenz (de Pasto Puna en Literatura y Folclore; 2. El folclore en la literatura. Bs. As., CEAL, 1980. Colección Capitulo $\mathrm{N}^{\circ}$ 58)

4. El lobizón de Horacio Quiroga (de 1906 en Selecciones Folcloricas. Bs. As., 1965)

5. Un lobizon en los fortines de Ricardo Rios Ortiz (en Cuentos del Chaco heroico. Santa Fe, Colmegna, 1977)

6. El lobizon de S. P. Bayona (en Revista Nativa, Mayo de 1924, Afno I Nro.5)

7. Fases de la Luna de Sara Gallardo (de El pals del humo [1977] en Narrativa breve completa. Bs. As., Emecé, 2004)

8. Antes de que amanezca de Diego Angelino (en Con otro sol. Bs.As., Corregidor, 1976)

9. El lobisón de Horacio Riveros Sosa (en Teluria. Cuentos y relatos del noreste argentino. Resistencia, Norte Argentino, 1966)

10. El lobizón de Manuel Mujica Láinez (en Aqul vivieron. Bs. As., Sudamericana, 1949)

11. Licantropta de Enrique Anderson Imbert (en Narraciones completas. Bs. As., Corregidor, 1990. Vol. V)

\section{Bibliografia}

Barthes, R. (1957), Mythologies. Paris, Editions du Seuil.

Blache, M. (1982), Estructura del miedo. Narrativas folklóricas guaraníticas. Bs.As., Plus

Ultra, - Análisis estructural de una creencia de la zona guaranitica: el lobisón. En:

\footnotetext{
${ }^{8}$ Mircea Eliade da la misma explicación para la "explosión ocultista" que parece ocurrir de 1970 en adelante. Sostiene que este fenómeno es indicio de una honda insatisfacción hacia los progresos del racionalismo cientifico. Ver Eliade, $M$ Ocultismo, brujerta y modas culturales, Bs. As, Marymar, 1977.
} 
Cuadernos del Instituto Nacional de antropologia $N^{\circ} 8$. Ministerio de Cultura y Educación, Dirección Nacional de Investigaciones Culturales, 1971-1978.

Brunel, P. y Chevrel, I. (1994), Compendio de Literatura comparada. México, Siglo XXI.

Coluccio, F. (1990), Diccionario de creencias y supersticiones argentinas y americanas. Bs. As., Corregidor,

Eliade, M. (1977), Ocultismo, brujeria y modas culturales, Bs. As., Marymar.

Farson, D. (1976), Hombres-lobo, vampiros y aparecidos. Barcelona, Noguer.

Fondebrider, J. (2004), Licantropia. Historias de hombres lobo en occidente, Bs.As., Adriana Hidalgo.

Frazer, J. (1984), La rama dorada. Madrid, F.C.E.

Ginzburg, C. (1999), Mitos, emblemas e indicios. Barcelona, Gedisa.

Granada, D. (1896), Supersticiones del Río de la Plata. Montevideo, Barreiro y Ramos.

Romano, E. (1977), "La emigración de los lobizones: del imaginario popular a la industria cultural." En Revista de Investigaciones Folklóricas. Vol.12, Bs. As.

Schroeder, A. (1987), "Del 'licantropos' griego al 'lobizón' americano." En Actas del VIII Simposio Nacional de Estudios Clásicos, Tucumán, Imprenta de la FAU.

Verón, E. (1998), La semiosis social. Fragmentos de una teoria de la discursividad. Barcelona, Gedisa. 